\title{
Internal Auditors Placement, Recognition and Independence in Ghana: Evidence from Metropolitan, Municipal and Districts Assemblies in Central Region
}

\author{
Paul Andoh \\ Senior Assistant Auditor, Cape Coast Technical University
}

\begin{abstract}
The paper focused on exploring the level of internal auditors' (IAs) placement and recognition and the implications of their independence. The paper employs data from metropolitan, municipal and district assemblies (MMDAs) in Central Region of Ghana. This paper was conceived from the call to strengthen IAs' independence to facilitate their effectiveness. Three objectives were deevlped from the problem statement. Quantitative analytical procedure was used coupled with survey design. Mean scale and regression analysis was adopted in this paper. It was found that the threat to IAs' placement is high resulting in low perceived placement. It also emerged that the level of recognition of IAs is threatened as evidence by low level of recognition. The inferential evidence showed that IAs' placement and recognition significantly determine the level of IAs' independence. It is recommended that IA units should be restructured both by legislation and in practice to cure the lapses in IAs' placement and recognition in order to improve IAss' independence.
\end{abstract}

Keywords: Internal Auditors; Internal Auditors Placement, Internal Auditors Recognition and Internal Auditors Independence

DOI: $10.7176 /$ RJFA/11-8-01

Publication date: April $30^{\text {th }} 2020$

\section{Introduction}

The effectiveness of public finance management, including the management of aid flows, is critical to the efforts of developing countries in making progress toward poverty reduction and enhance social welfare and economic growth. Most often, weaknesses in public financial management often reflect underlying interests and incentives. However, the success of reforms and strengthening of public financial management mostly requires not only highlevel political leadership and support but also technical skills (Adafula et al, 2015; Asiedu \& Deffor, 2017; Ibrahim et al, 2017). To become successful in strengthening public financial management, the use of internal auditors in the public sector is increasing gaining attention (Hay \& Cordery, 2018; Vadasi, Bekiaris, \& Andrikopoulos, 2019)

However, within the Metropolitan, Municipal and Districts Assemblies (MMDAs) the expected requirements and independence of internal auditors is believed to be compromised by their level of placement and recognition (Hay \& Cordery, 2018). (Adafula et al, 2015; Asiedu \& Deffor, 2017; Ibrahim et al, 2017; Pappa, \& Filos, 2019). Most of the internal auditors are within ranks which are lower than those who make budgetary allocations and the office holders they are supposed to hold into account. The possible implication of this lower rank phenomenon is that the internal auditors may not have the power or authority to prevent mismanagement of funds. Additionally, since the internal auditors are subordinates of most spending officers who have power to engage in corruptible practices, the auditors are perceived to be incapacitated in workforce management will never fall behind the times. Therefore, it is worth an attempt to incorporate a novel methodology, such as HMS, into the state of the art of workforce sizing. sanctioning these officers for fear of victimisation. George, Konstantinos and Theofanis (2015) argue that for a minimum, internal auditors functional reporting should be to a level possessive of adequate authority to promote their independence, to ensure wide functional scope, sufficient thought on engagement communications and sufficient action on audit recommendations. However, this recommendation is yet to receive attention in the Ghanaian setting.

Another staggering problem that is believed to comprise the independence of internal auditors is the level of recognition given to them in the MMDAs (Asiedu \& Deffor, 2017). The internal auditors are perceived to the watchdogs to the political authorities and other heads of the MMDAs who have the tendency to mismanage public funds. However, these political authorities and other heads of the MMDAs are alleged to be the ones who disregard directives of the internal auditors. The perceived poor recognition given to the internal auditors arguably undermines their independence (Yakubu, 2017).

The workplace challenges of these internal auditors in respect of placement and recognition in the public sector could threaten the independence of the internal auditors and limit internal audits' potential to contribute the much-desired value adding capabilities to national and organisational goal achievement in the Ghanaian MMDAs (Sakour \& Laila, 2015; Vadasi, 2019). Therefore, the urgent need to refocus attention on internal auditors' role in protecting public purse requires the considerations of their placement, recognition and independence. Furthermore, the effectiveness of internal auditors' roles in enhancing high quality of public services, achieve good internal 
control system, minimise/eliminate corruption, promote accountability, ensure the practice of good corporate governance system, and greater transparency, their independence is an anchor (Appiah \& Abdulai, 2017; Yakubu, 2017). In the 2016 and 2017 end of service year reports by the auditor general, it was stated that the state lost a colossal sum of GHф2.2 billion. The reports indicated that this was due to irregularities and lack of probity in the actions and decisions by public officer (Annual Report of Auditor General, 2017). Almost all the fundamental principles required for effective internal audit function is tied up to the independence. To objectively assess the operational environment and financial management procedural implementations and controls and to increase accountability of managers of the public sector and reinforcement of trust and confidence in financial reporting processes within the administration, internal auditors require independence in thought, in law and in appearance (Asiedu, \& Deffor, 2017; Dal Mas \& Barac, 2018). The implication is that it is critical to explore factors which could be perceived to threaten this anchor (independence) and investigate the extent to which these factors significantly influence the level of independence.

It is against this backdrop that the current paper seeks to explore the perceived level of placement and recognition and determine the extent to which these antecedents influence the independence of the internal auditors in the MMDAs using data from Central Region of Ghana. The paper develops three specific objectives which are tied to the problem under investigation such that by addressing these objectives, the problem is addressed. These specific objectives are as follows:

- Determine the perceived level of placement/position of internal auditors in the MMDAs in the Central Region

- Investigate the perceived level of recognition of internal auditors in the MMDAs in the Central Region

- Investigate the effect of perceived level of placement/position and recognition on independence of internal auditor's in the MMDAs in the Central Region

\section{Literature Review}

This section of the paper provides both theoretical and empirical background to the subject under study. The theoretical framework presents the theoretical arguments to support the focus of this study. The empirical review presents the current development in the subject of the investigation and how the focus of this paper fits into the debates of the current development.

\subsection{Theoretical Review}

This paper employs two fundamental theories to back the study framework. Not all theories are specifically unique. The assumptions of varying theories could be consolidated to explain a phenomenon in order to present theoretical framework for an investigation. The two theories adopted in this paper are agency cost theory and contingency theory.

\subsubsection{Agency Cost Theory}

Agency theory is all about the relationship among the organisation owner(s) and its top management (Adams, 1994). It supports a positivist group of philosophy (Adams, 1994; Changwony \& Rotich, 2015). In corporate form of organisations, the top management manages the whole organisation on behalf of the owners as an agent. It is however due to this that Jensen and Meckling (1976) focused on the relationship between the agents and the principals with the argument that managers (agents) engage in actions that promote their own interests at the expense of principals and proposes solutions to the unaligned goals and different risk profiles.

In his article Adams (1994) stated that agency theory can provide for richer and more meaningful research in the internal audit discipline. In his view, agency theory contends that internal auditing, in common with other intervention mechanisms like financial reporting and external audit, helps to maintain cost-efficient contracting between owners and managers. In the case of the public administration, managers are the spending authorities while the general public whose interest the administration serves become the owners. It is in this light that the independence of internal auditors is paramount in order to protect the resources entrusted to the public administration for the benefit of the general public.

The implication of the theory to the current study setting is that, entrusted with the public resources to protect, internal auditors should be given maximum independence to ensure efficient public financial management. However, the situation where internal auditors work under the public officers of MMDAs whom they are to hold into account, gives these managers the opportunity to freely misuse the public funds to their own benefit ahead of the public (Ayagre, 2015; Tackie, Marfo-Yiadom, \& Achina, 2016). This almost always become possible because, the internal auditors who have the competency to stop such mismanagement do not possess the managerial power to do it.

The agency theory entails entrusting resources in the hands of the agents ( management of MMDAs) and these agents in turn should produce reports on the day-to-day running of the business, this is usually in both quantitative and qualitative manner (Asiedu \& Deffor, 2017; Ibrahim et al, 2017; Pappa, \& Filos, 2019). The agents entrusted with resources are assumed to have a sense of accountability in demonstrating how the resources have 
been used. The purpose of the auditor is to promote confidence-reinforcing trust in financial information. However, if the presence of the internal auditor is disregarded by the agents, the needed information would not be given causing information gap in the financial report of the auditors. This is why the perceived level of recognition of internal auditors is necessary if public financial management could be efficient. Additionally, in contributing to the agency cost theory, Queku (2017) argued that managers' main goal is to maximise their personal goal to the extent that the principals are unaware and this is made easy by the separation of business ownership and the business control. The implication of Queku's argument is that public officers could be motivated to misappropriate public funds to the extent that such aberrant activity cannot be revealed and reported. The inability of the internal auditors to reveal or to report possible misappropriate may arise from lower level of placement and absence effective recognition system. Thus, this theoretical assumption may explain why news of misappropriation in the Ghanaian public sector is received mostly through the Auditor General's Report in Ghana. This therefore brings into question the level of placement and recognition system for the internal auditors in Ghanaian public sector. This paper therefore seeks to present empirical evidences about this situation using data from the Central Regions. The paper follows these theoretical assumptions to formulate the first two research questions as follows:

RQ1: What is the perceived level of placement/position of internal auditors in the MMDAs in the Central Region?

RQ2: What is the perceived level of recognition of internal auditors in the MMDAs in the Central Region?

It can be argued from the theoretical assumptions further that the level of placement and recognition are important precursors for the internal auditors' independence and their effectiveness. Weakness in the placement and recognition of internal auditors could make it difficult for them to independently compel spending officers to work towards achieving goal congruence and ultimately reduce their effectiveness (Nermeen, 2014, Queku, 2018). This theoretical extrapolation is consistent with the appeared differences in the results of the work of the external auditor and the internal auditor. The paper therefore follows this theoretical position to formulate a hypothesis as:

H1: The Level of Placement and Recognition of Internal Auditors have significant effect on the level of Independence

2.1.2 The Contingency Theory

The contingency theory was founded by Edward Fiedle in 1964. The theory emphasis the relationship between leadership and how leaders operates in certain situations Dawuda et al (2017). This is applicable within the public administration and the role of auditors. The goal of an audit is to test the reliability of a company's information, policies, practices and procedures. In the case of the public administration and for that matter the MMDAs, the objective is to make sure that public financial management procedures and regulations are strictly followed to protect public purse. Within the public financial management laws, government regulations require that in the public administration undergo financial audits (Yakubu, 2017).

Regardless of the audit subject, various factors impact an administrations of final results, and the contingency theory takes these factors into account during the audit process (Appiah \& Abdulai, 2017). Some of these factors include the level of recognition and placement of the internal auditors. When auditors are highly regarded or given maximum recognition within the administration, leaders will seek their advice in all critical decisions where finance is involved. This will help strengthen financial discipline. On the other hand, if the level of recognition and placement given to them is low, their input would not be regarded in financial decision-making processes, thereby leading to huge loss of money to the state. The theoretical implication is that independence of the internal auditors' may be contingent on the auditors' placement and recognition. This affirms the earlier hypothesis as follows:

Perceived level of placement/position and recognition has significant effect on the independence of internal auditors in the MMDAs

This suggests that by the contingency theory, internal auditors in the MMDAs independence could be assured and be effective when auditors form part of top management decision makers (Scott, 2019). On the other hand, if their independence is compromised by low recognition and limited decision-making power, their level of skills and expertise may not even make them achieve their goal.

\subsection{Empirical Review}

In Ethiopia, Ariga and Gathogo (2016) identified internal audit reporting level as significant criteria in influencing internal audit independence and ultimately internal audit effectiveness. According to Dusoruth (2016) in countries where the role of internal audit is highly valued, functional reporting by internal audit has shifted from senior officers in organizations to audit committees of the boards. According to Nwaobia, Ogundajo and Theogene (2016) accorded sufficient independence autonomy, functional infrastructure and human capital, internal audit would positively influence audit effectiveness, transparency and accountability of financial management in public sector. These studies give empirical reason to believe that placement or position is important for internal auditors to be independent. However, though the settings are within developing countries, these studies are outside the Ghanaian jurisdiction. Hence it is important to investigate the case of the Ghanaian public sector to widen the ongoing debate 
in the developing countries.

In Kenya, Mokono and Nasieku (2018) evaluated the effect of working environment, establishes the effect of internal auditor's independence and the effect of internal auditors' competence on the performance of internal auditor in public universities. The study adopted descriptive research design with a target population of the chief internal auditors from 31 chartered public universities. Primary data was used for analysis. The study found that the internal auditors working environment, internal audit independence and authority, internal auditor's technical competence impacted on the performance of internal audit function. The implication of the study finding is that auditors should consider complying with professional standards as the most important contributor to internal auditing performance. The findings of Mokono and Nasieku (2018) demonstrate how critical independence is to the effectiveness of internal audit. Thus, it is useful to determine how the current structural bottlenecks in the internal audit architecture of the Ghanaian public sector (placement/rank and recognition) drives the level of their independence. Empirical evidence from such investigation would not only contribute to theories but also practice and policy.

Like the current study, Nyaga, Kiragu and Riro, (2018) explored the relationship between internal audit independence and internal audit effectiveness in the in Kenya. A descriptive research design was adopted. The target population of the study consisted he forty-six (46) staff members from the Directorate of Internal Audit of Kirinyaga County Government. Primary data was collected through a self-administered questionnaire composed of closed ended questions. The findings indicated that the audit function was less than independent in evidence analysed. Regression analysis revealed that internal audit independence had positive and significant effect on internal audit effectiveness. The study concluded that internal audit independence was an important predictor of the effectiveness of the audit function in the county government. Like Mokono and Nasieku (2018), Nyaga and Co identified internal auditor's independence as precursor to audit effectiveness. Much as the current study do not doubt this assertion, it could be observed that mechanisms for attaining such audit independence is conspicuously missing in these existing studies. Thus, in an attempt to enrich the existing literature, the current focus on how auditor's independence is affected by recognition and placement in the public sector.

In the Ghanaian setting, Musah, Gapketor, and Anokye (2018) examined factors that determine internal audit effectiveness among State Owned Enterprises (SOEs) in Ghana. The study specifically examined the respondent's perception about the impact of factors such as; competence of internal audit unit, size of internal audit unit, relation between internal and external auditors, management support for internal audit function, and independence of internal audit unit on internal audit effectiveness among SOEs in Ghana. The results of the study showed that management support for internal audit function is the most significant determinants of internal audit effectiveness. The study further revealed that size of internal audit unit, competence of internal audit staff, independence of internal audit unit as well as good relationship between internal and external auditors were significant determinants of internal audit effectiveness. The practical implication of the study to the current discussions is the identification of audit independence as an antecedent to effectiveness. However, the current study expands the scope of independence to include recognition of internal auditors within the public sector administration

In the Ketu Municipal Assembly in Ghana, Agbevade (2018) examined the effectiveness of internal audit in the Education office. The finding of this research proved that the management support, the existence of adequate and competent internal audit staff, and approved internal Audit standards and legislations were statistically significant and positively related with the internal audit effectiveness in the public education offices. Thus, the education office should give more support for the internal audit functions by facilitating the internal audit work and give sufficient in-service training and resources for the existing internal audit staff. It could be observed that the study setting of Agbevade is similar to the current study. However, its focus was on competencies of internal auditors. The currents study argues in spite of how competent an internal auditor would be, if their authority to perform is limited, they cannot function effectively. The study further asserts from the contingency theory that if internal auditor's advice is not sought in critical financial decision-making processes, mismanagement of funds will continue to linger in the yearly report of the Auditor General. Thus, extending the existing literature to establish the level of perceived recognition, placement and consequence on independence of the internal auditors which is the subject of this investigation is timely.

In another vein, Chaiwong (2019) examined the factors affecting efficiency in internal audit performance and the relationships between efficiency in internal audit performance and operational outcomes, based on a survey carried out on the "Set 100" companies listed on the Thai Stock Exchange. The efficiency in internal audit performance consists of four dimensions, namely independence, objectivity, competencies and human relations. The result of regression provides that completeness of operating and information systems, understanding and acceptance within the organization, knowledge, skill, and human relations and relationship between the internal audit units and other units have influence on internal audit efficiency. In addition, human relations and the relationship between the internal audit unit and other units have an influence on the four dimensions of an internal audit's performance. Chaiwong (2019) study also emphasized the critical role of independence. The current study helps to fill this gap by examining proper recognition of internal auditors serves as predictor to auditors' 
independence

\subsection{Conceptual Issues}

This paper of the paper discusses some of the key study variables in the literature. The key concepts include internal audit system in Ghanaian public sector, internal auditors' independence, placement and recognition. These concepts are reviewed as follows:

\subsubsection{Internal Audit System in Ghanaian Public Sector}

Internal Audit Agency (IIA) in 1999 defined an internal auditing as an independent evaluation, and assurance as well as consulting activity which is designed to improve and add value to an organisation's operations. Thus, following this definition, internal audit of the Ghanaian public sector may be defined as independent assessment and evaluation of public financial management practices, policies and procedures within the framework of the designed system of controls to add value and improve the operations of the public sector. The auditing of the public sector is guaranteed by the 1992 Constitution of Ghana and the Internal Audit Agency (IAA) Act, 2003 (Act 658). Despite these legal provisions, the internal audit system in Ghana has lacked administrative recognition until recently (Onumah \& Krah, 2012; Simpson, 2012).

The establishment of IAA has responded to some of the challenges in the internal audit functions. The IAA in Ghana is actively involved in institutionalising and establishing internal audit units in various MDAs and MMDAs. The agency has also contributed to issuing internal audit standards to guide practitioners of IA in the various MDAs and MMDAs (Simpson, 2012). Nevertheless, the core facet of the internal audit system as noted in the definition-independence has often been called into question. It is therefore critical to explore some of the antecedents which could sacrifice the effectiveness of the IA functions through weakness in the independence of the internal audit.

\subsubsection{Internal Auditors' Independence}

Internal audit independence and authority are important concepts that enable the internal auditor to operate without interference and provide effective feedback to management on how to continuously enhance effective control policies (Dusoruth, 2016). It could be argued that the increased frequency of financial reporting and external audit failures motivated the internal audit profession to seek greater autonomy in the organisation structure and in countries where the role of internal audit is highly valued, functional reporting moved from senior officers in the organisation to specific committees set-up under the boards and that report to the board of directors. The auditing services offered by internal auditors are achieved through internal auditor's independence and where internal auditors lack independence, they would normally fail to perform to the expectation of the organization (Ariga \& Gathogo 2016).

The lack of controls also results in, late filings, financial reporting errors, fraud as well as numerous other questionable transactions being performed. As the number and size of public organisations grow so does the need for properly educated and experienced accounting related personnel and the protection of the internal auditors' independence. The weakness in the independence of internal auditors could management to influence the decisions of internal auditors affecting their performance and this results in financial reporting risks such as improper revenue recognition, inflated acquisition costs for equipment and inventory, improper cash advances to officers and other transgressions that have a significant impact on organizational viability (Mokono \& Nasieku, 2018).

\subsubsection{Internal Auditors' Placement/Rank in MMDAs}

In the MMDAs in Ghana, the internal audit unit comes under the head of services and the chief directors. Additionally, audit unit reports to the appointed sector ministers and the municipal or district chief executives. This line of reporting is what is argued to compromise the independence of the internal auditors. In view of this Ariga and Gathogo (2016) argued that to build appropriate level of independence for internal audit effectiveness, the chief audit executive should report administratively to the senior executives and functionally to the board. Dusoruth, (2016) supported the idea as his study revealed a case of significant and positive association between internal audit level of reporting or organisational status and its effectiveness. Internal audit function must be accorded sufficient authority and status to enable objective execution of their mandate though their employment status could hinder their way.

Similarly, Dusoruth, (2016) stressed that independence and objectivity can enhance audit effectiveness through internal audit reporting. Similarly, Nwaobia et al (2016) identified internal audit reporting level as significant criteria in influencing internal audit independence and ultimately internal audit effectiveness. It has been observed that in countries where the role of internal audit is highly valued, functional reporting by internal audit has shifted from senior officers in organisations to audit committees of the boards (Mokono \& Nasieku, 2018). These literature suggests that the placement of the internal auditor in the public sector could significantly affect their independence. This assertion could be affirmed or disaffirmed through higher order statistical evaluation.

\subsubsection{Internal Auditors' Recognition in MMDAs}

The concept of recognition is defined to how public service give all needed information to internal auditors and 
involve them in all financial decision-making processes. In view of this, Ayagre, (2015) states that to ensure sufficient independence and enhanced effectiveness of audit function, it should be accorded right of access to books of account, financial statements, information and explanations at all times. It has also been indicated that with the right information, internal auditors could function effectively and decisively (Nwaobia et al, 2016).

\subsection{Conceptual Framework}

From the theoretical and empirical review, it has been revealed that given the right position and recognition, internal auditors' independence could be guaranteed. This would make them exhibit professionalism and ensure efficient public financial management. Figure 1 gives diagrammatical presentation of the interrelationship between the concepts. The figure shows a direct relationship between placement and recognition at one end and independence at another end. The paper assumes that a reasonable level of placement or rank of internal audit could enhance the level of independence as the deterrent of victimisation may be immaterial. Similarly, the level of recognition is also expected to positively affect independence.

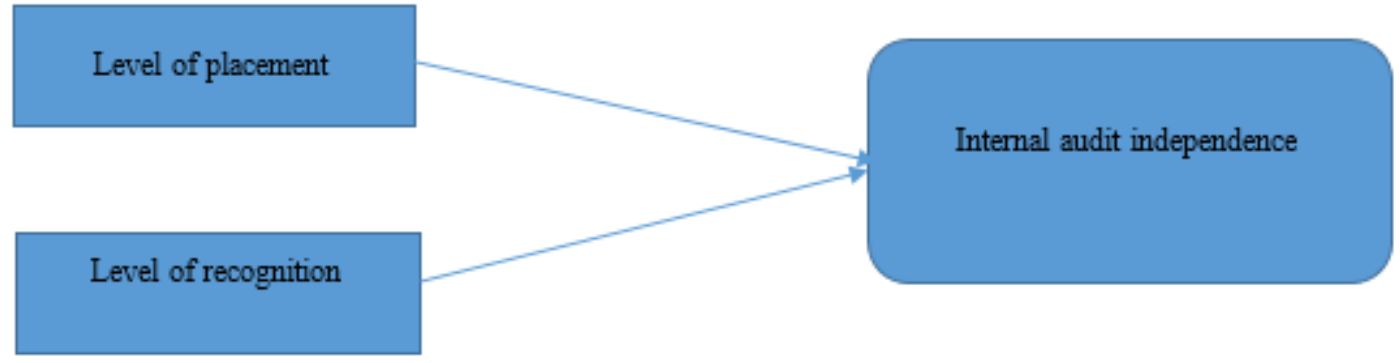

Figure 1: Relationship between Placement, Recognition and Independence of Internal Auditors

\subsection{Research Design and Approach}

The current study adopted a survey design to investigate internal auditors' placement and recognition in the public sector and its impact on their independence. The focus is on the MMDAs in the Central Region of Ghana. Bell, Bryman and Harley, (2018) a survey design is a method of collecting information by interviewing or administering a questionnaire to a sample of individuals. It is applicable in collecting data about people's attitudes, opinions, habits, education and social issues. This design is supported by the quantitative approach. The use of survey design provides room to gather both numerical data which is consistent with the quantitative approach.

\subsection{Target Population, Sampling Technique and Instrument Design}

The population of the study consisted of all the twenty-three (23) MMDAs in the region. The units of analysis are the internal auditors, audit committees and chairman of finance and administration committee. In all the target population is 57 made up of the internal auditors, audit committees and chairman of finance and administration committee in the MMDAs. The papers employs sample size of 46 based on reasonable ratio of $80 \%$. The sampled participants are presented with suitable instrument. The paper uses primary data source. The data are collected through a self-administered questionnaire which is composed of closed ended questions for the quantitative analysis and open ended questions to capture the qualitative response. The questionnaires are distributed through a drop and pick method whereby the researcher allowed the respondents to answer the questions at their own pace. The data collection instrument is based on some existing instruments which have already been validated with high reliability score.

\subsection{Data Analysis}

The collected data are cleaned and edited to ensure completeness and consistency. The data are tabulated and analysed using descriptive and inferential statistics with the help of statistical package for social sciences (SPSS version 22) which is a tool among others for data analysis. The mean scale analysis is used to determine the perceived level of placement/position and recognition of internal auditors in the MMDAs. Standard regression analysis is used to determine whether the perceived level of placement/position in aggregation have significant effect on internal auditors' independence. The results are presented in form of tables, frequency distributions. According to Fellows and Liu, (2015), this method conserves space, reduces explanatory and descriptive narratives. It also facilitates the process of comparison. The relationship between the study variables was established using the following model:

$\mathrm{Y}=\beta_{0}+\beta_{1} \mathrm{P}_{1}+\beta_{2} \mathrm{R}_{2}+\varepsilon$

Where:

$\mathrm{Y}=$ Internal Auditor independence

$\beta 0=$ Constant Term 
$\beta_{1}=$ Beta coefficients

$\mathrm{P}_{1}=$ perceived level of placement

$\mathrm{R}_{2}=$ Perceived level of recognition

$\varepsilon=$ Error Term

\subsection{Results and Discussions}

Out of the 46 questionnaires administered 39 was received. This represents a response rate of about $85 \%$. This response rate is above $70 \%$ which is referred to as very good according to Kothari (2007). The Tables to follow give descriptive analysis of internal auditors' independence, perceived level of placement and perceived level of recognition.

Table 1: Descriptive Analysis of Internal Audit Independence

\begin{tabular}{lccc}
\hline Checklist & N & Mean & Std. Dev \\
\hline Management determines the scope of internal audit work. & 39 & 3.1098 & 0.3556 \\
Budget of internal audit is controlled by management & 39 & 4.1017 & 0.2611 \\
Undue involvement of management in internal audit planning & 39 & 3.3511 & 0.9915 \\
$\begin{array}{l}\text { Active involvement of internal auditor in the daily management } \\
\text { activities }\end{array}$ & 39 & 3.6461 & 1.2417 \\
Internal audit function does not report findings directly to the audit & & & \\
committee & 39 & 3.3317 & 0.8621 \\
Internal audit function has difficult access to audit evidence. & 39 & 2.9924 & 0.2517 \\
Total Aggregation & $\mathbf{3 9} \mathbf{2 0 . 5 3 2 8}$ & \\
Grand Mean & $\mathbf{3 9} \mathbf{3 . 4 2 2 1}$ & \\
\hline
\end{tabular}

Scale (Mean): Low = 1.00 - 2.90; Cut-off Point =2.99; High = 3.00-5.00

Source: Field Survey (2020)

The assessment of the level of internal audit independent is based on six (6) points scale instrument and scored on 1 to 5 . From 1 to 2.9 is low threat to independence, 2.99 is the cut-off point while 3 to 5 is at the region of high threat. The summation of the mean scores of the six indicators that make up the threat to the Internal Auditor Independence is 20.5328 and this further indicates that there is a high level of threat to independence compared to the total score of 30.00. To buttress the evidence of high threat to evidence, the overall mean score as found in Table 1 is $3.4221(20.5328 / 6)$. In conclusion, the independent threat factors such as budget of internal audit is controlled by management (mean $=4.1017$ ), active involvement of internal auditor in the daily management activities ( mean $=3.6461$ ), undue involvement of active involvement of internal auditor in the daily management activities (mean=3.6461), undue involvement of management in internal audit planning (mean =3.6461), internal audit function does not report findings directly to the audit committee (mean $=3.3317$ ), management determines the scope of internal audit work (mean=3.1098), Internal audit function has difficult access to audit evidence (mean=2.9924). It is further evident that budget of internal audit controlled by management was rated the highest threat to the independence of the internal auditor while Internal audit function has difficult access to audit evidence was the least threat. Given the high threat of independence of 3.4221, the level of independence is estimated as $1.5779(5.00-3.4221)$

The first research question of this paper sought to explore the level of internal audit placement. The results are captured in Table 2. The research question is recalled as

Research Question 1: What is the perceived level of placement/position of internal auditors in the MMDAs

in the Central Region?

To answer this research question, five indicators were used to measure the variable on a five-point likert scale. Score ' 5 ' indicates the strongest agreement while score ' 1 ' shows the least agreement. Given this measurement scale, the overall highest score expected is 25.00 (i.e. 5 indicators X 5 point on the scale) and the lowest is five (i.e. 1 indicator X 5 on the scale). The assessment of the weakness in the level of internal audit placement has a range of 1 to 2.9 as low threat to internal auditors' placement/rank, 2.99 is the cut-off point while 3 to 5 is at the region of high threat. 
Table 2: Descriptive Analysis of Internal Audit Perceived Level of Placement/Position

\begin{tabular}{|c|c|c|c|}
\hline Checklists & $\mathbf{N}$ & Mean & Std. Dev \\
\hline Internal auditors report to is of the same authority of all management. & 39 & 4.1298 & 0.1579 \\
\hline I have a concern that I may lose my job due to interferences from top-management & 39 & 3.8765 & 0.2517 \\
\hline $\begin{array}{l}\text { Top-management in my district provides me with guarantees when I need them } \\
\text { and vice versa }\end{array}$ & 39 & 3.0987 & 1.1452 \\
\hline Internal auditors work and report findings to internal management & 39 & 3.9317 & 1.0606 \\
\hline $\begin{array}{l}\text { Internal auditors position and function can be changed or influenced by internal } \\
\text { management }\end{array}$ & 39 & 4.3424 & 0.0510 \\
\hline Total Aggregation & 39 & 19.3791 & \\
\hline Grand Mean & 39 & 3.8758 & \\
\hline
\end{tabular}

Scale (Mean): Low = 1.00-2.90; Cut-off Point =2.99; High $=3.00-5.00$

Source: Field Survey (2020)

The grand score of the five indicators that make up the threat to the Internal Auditor placement/rank or position is 19.3791. This findings indicates that the respondents generally believed that there is a high level of threat to the internal auditors' placement, rank and position compared to the total score of 25.00. The grand mean as shown in Table 2 is $3.8758(19.3791 / 5)$. In fact, the results revealed that all the threat indicators have high scorethey fall within the high region. The highest score was given to the indicator 'internal auditors' position and function can be changed or influenced by internal management' with mean score of (mean=4.3424). Thus, the biggest threat to their placement is the fear that internal management can change or influence their position which could take the form of transfer. The minimum score is 3.0987 associated with 'top-management in my district provides me with guarantees when I need them and vice versa'. Even this minimum score is still within the high region making the threat to their placement quite alarming.

The findings disaffirm the results of Dusoruth (2016) which revealed that placement of internal auditors has been shifted and upgraded to the extent that their reporting line has shifted from reporting to senior officers to audit committee. The seemingly contradiction may be attributed to the study setting of Dusoruth (2016). According to Dusoruth (2016) functional reporting by internal audit has shifted from senior officers in organisations to audit committees of the boards in countries where the role of internal audit is highly valued. The implication of the low placement as exhibited by the mean score of 1.22 (5.00-3.88) is that Ghanaian public sector (MMDAs) does not place high value on internal audit function. This finding is consistent with the discovery and opinion of several prior researchers in the field According to some of the prior researchers, the anxiety for losing one's job, fear of transfer and weakness in reporting structure affect internal auditor level of placement (Mokono \& Nasieku, 2018; Nawaiseh \& Alnawaiseh, 2015; Nwaobia et al, 2016; Thunaibat, 2015).

Overall, the findings have revealed that internal auditors in the MMDAs do not have proper placement and there are threats to their positions. The findings imply that the internal audit function in the Ghanaian public sector (MMDAs) should be an objective task with degree of assurance and trust. Therefore, internal audit should not be compromise in the reporting line, where they required to report and review the operational areas. These findings have theoretical and practical significance. The findings support the assumption of contingency theory. The findings suggest that internal auditors' placement is contingent on their authority in comparable to management, level of threat to lose their job, internal auditors need for guarantees from management and whether or not internal auditors position and function can be changed or influenced by internal management (Ibrahim et al, 2017; Nyaga,et al 2018; Pappa, \& Filos, 2019).

The second research question of this paper sought to explore the level of internal audit recognition. The results are presented in Table 3. The research question is recalled as

Research Question 2: What is the perceived level of recognition of internal auditors in the MMDAs in the

Central Region?

Similar to the first research question, to answer this research question, five indicators were used to measure the variable on a five-point likert scale. Score ' 5 ' indicates the strongest agreement while score ' 1 ' shows the least agreement. The overall highest score expected is 25.00 (i.e. 5 indicators X 5 point on the scale) and the lowest is five (i.e. 1 indicator X 5 on the scale). 


\section{Table 3: Descriptive Analysis of Internal Audit Perceived Recognition}

\begin{tabular}{lccc}
\hline Checklist & N & Mean & Std. Dev \\
\hline Internal auditors do not play critical role in management decision making. & 39 & 3.6998 & 0.7579 \\
Internal auditors usually subordinated in terms of my decision during an audit to & & & \\
management & 39 & 4.1981 & 0.8921 \\
Internal auditors do not play role in directing and controlling the use of funds at the & & & \\
local assembly & 39 & 3.5317 & 1.0606 \\
Internal auditors do not receive comparable respect to external auditors in the public & & & \\
services for their essential role in public financial management & 39 & 4.3561 & 0.4317 \\
Internal auditors' views are not sought by management on budgetary allocation & 39 & 4.2581 & 1.0712 \\
Total Aggregation & $\mathbf{3 9}$ & $\mathbf{1 9 . 8 6 3 8}$ & $\mathbf{3 9 . 9 7 2 8}$ \\
Grand Mean & $\mathbf{3 9}$ & $\mathbf{3 . 9 7 2 8}$ \\
\hline
\end{tabular}

Scale (Mean): Low = 1.00-2.90; Cut-off Point =2.99; High = 3.00-5.00

Source: Field Survey (2020)

The summation of the individual score of the five indicators that make up the threat to the Internal Auditor recognition is 19.8638 and grand mean of 3.9728. The participants generally believed that the level of recognition of the internal auditors is very low as shown by grand mean of 1.03 (mean=5,00-3.97). It can be observed in Table 3 that all the five indicators have mean score of greater than 3.00. Three of the indicators mean scores are more than 4.00 while two had mean scores are more than 3.00. The respondents rated 'internal auditors do not receive comparable respect to external auditors in the public services for their essential role in public financial management' as the highest threat to the internal auditors' recognition (mean=4.3561, $\mathrm{SD}=0.4317$ ). The least mean score is 3.5317 associated with 'internal auditors do not play role in directing and controlling the use of funds at the local assembly'. This least mean score is still within the high region.

The data shows that internal auditors are not respected with the public services for their essential role in public financial management neither are their views sought by management on budgetary allocation. The information in Table 3 further indicates that internal auditors usually subordinated in terms of my decision during an audit to management. All these obstacles compromise their independence. Empirically, studies from Marfo-Yiadom, and Achina, (2016), Mokono and Nasieku (2018), Agbevade (2018) and Chaiwong (2019) have all confirmed that low level of recognition to internal auditors is disingenuous to their independence which translate into affront on efficient public financial management.

The findings confirm theoretical hypothesis from the agency theory. It stated that if the presence of the internal auditor is disregarded by both the principal (the public as evident the laws, regulations and structures) and the agents (management of MMDAs), the intervention mechanisms needed to bridge the gap would rather widen the gap (Asiedu \& Deffor, 2017; Ayagre, 2015; Tackie, Marfo-Yiadom, \& Achina, 2016). This is why the perceived level of recognition of internal auditors is necessary if public financial management could be efficient.

Effect of Threat of Internal Auditors' Placement and Recognition on the Independence

To determine how internal auditors' placement and recognition affect their independence, the study adopted inferential statistics where standard regression analysis was employed. This is the last study objective that examined the effect of perceived level of threat of recognition and perceived level of placement on the independence of internal auditors. Inferential statistics through regression analysis was used to test the accompanying hypothesis. The hypothesis is recalled as:

\section{$H_{1}$ : The Level of Placement and Recognition of Internal Auditors have significant effect on the level of Independence}

This type of statistical analysis requires some underlying assumptions like the absence of multicollinearity problem. The basic assumption for regression to generate reliable results is the absence of multicollinearity problem. Using SPSS, the study used 'Tolerance Value and Variance Inflation Factor (VIF)' as the bases for testing this assumption. Tolerance value is the inverse of VIF. The norm is that when tolerance value is very small (i.e. less than 0.1 ) and VIF greater than 10 , then there is multicollinearity problem

Table 4: Multicollinearity Analysis

\begin{tabular}{llll}
\hline Study Variables & Tolerance Value & VIF & Decision \\
\hline TIN & .392 & 2.548 & No \\
TLP & .700 & 1.429 & No \\
TLR & .920 & 1.087 & No \\
\hline
\end{tabular}

Note TIN denotes Threat to Independence, TLP is Threat to Level of Placement, TLR is Threat to Level of Recognition

It can be observed from Table 4. that all the variables have tolerance values of greater than 0.1 and VIF values less than 10. This suggests that the model has not violated the multicollinearity assumption. 
Inferential Analysis

Table 5: Estimation of Threat to Recognition and Placement on Threat of Independence

\begin{tabular}{lllllll}
\hline & Beta & t-stat & Sig. & $\mathbf{R}^{\mathbf{2}}$ & $\mathbf{A d j R}^{\mathbf{2}}$ & f-stat \\
\hline AIN Model & & & & 0.781 & 0.760 & $11.255(.001)$ \\
TLP & 0.481 & 4.475 & 0.0351 & & & \\
TLR & 0.221 & 5.175 & 0.0201 & & & \\
\hline
\end{tabular}

Note TIN denotes Audit Independence, TLP is Perceived Level of Placement, TLR is Perceived Level of Recognition

From the internal audit model, the value for $\mathrm{R}$ square was 0.78 . This illustrates that there is a relationship between perceived threat of placement and recognition on the independence of internal auditors in the MMDAs in the Central Region. The adjusted $\mathrm{R}$ squared $\left(\mathrm{R}^{2}\right)$ value of 0.760 shows that 76.0 percent of the independence of internal auditors in the MMDAs in the Central Region is explained by perceived level of placement and recognition. The remaining 24.0 percent is explained by other factors not in the model. The model was significant with the $\mathrm{F}$ statistics $=11.255$ at $\mathrm{p}$ value 0.000 which is less than 0.05 . This is an indication that perceived level of placement and recognition when considered jointly has significant effect on independence of internal auditors.

The inferential analysis indicated both threat of perceived level of placement and recognition have positive significant influence on the threat of independence of internal auditors. The perceived threat to the level of placement and recognition have coefficient of $0.481(0.0351)$ and $0.221(0.0201)$ respectively. These coefficients are positive suggesting that threat of placement and recognition of internal auditors have positive effect on threat of independence of the internal auditor. The p-values are in the parentheses. These p-values are less than 5\% indicating that the coefficients are significant and therefore there are significant relationship.

The implication is that an increase in the level of threat to placement and recognition would lead to about 0.481 and 0.221 point increase in the threat of independence (i.e. decrease the internal auditors' independence). On the other hand, a decrease in the level of threat to placement and recognition would lead to about 0.481 and 0.221 point decrease in the threat of independence (i.e. increase the internal auditors' independence)

The findings from the perceived level of placement and recognition explains why the overall mean score for the level of independence was found to be as low as 1.5779 (and threat of independence as high as 3.4221) given the high threat to placement and recognition. The implication is that threats to placement and recognition have significant negative effect on the level of internal auditors' independence (i.e. positive influence on the threat of independence).

The negative effect of high threat to internal auditors' placement and recognition on internal auditors' independence) is consistent with the findings by Ayagre, (2015). Similar to this paper, Ayagre, (2015) revealed that to ensure sufficient independence and enhanced effectiveness of audit function, it should be accorded the needed recognition. It has also been indicated that with the right recognition and placement, internal auditors could function independently and decisively (Nwaobia et al, 2016). The findings also support the general opinion in some prior research efforts. The results contribute to the assertion by Ariga and Gathogo (2016). Ariga and Gathogo (2016) argued that to build appropriate level of independence for internal audit effectiveness, the chief audit executive should report administratively to the senior executives and functionally to the board. Dusoruth, (2016) supported the idea as his study revealed a case of significant and positive association between internal audit level of reporting or organisational status and its effectiveness and independence. Thus, empirically, there is evidence of negative relationship between threat to placement and recognition of IAs and the level of IAs independence.

The findings also contribute to theory. The findings affirm the contingency theory as evident that IAs independence is dependent on the level of recognition and placement. Thus, threats to IAs placement and recognition threaten IAs independence (Appiah \& Abdulai, 2017). This suggests that by the contingency theory, internal auditors in the MMDAs independence could be assured and be effective when auditors form part of top management decision makers (Scott, 2019). On the other hand, if their independence is compromised by low recognition and limited decision-making power, their level of skills and expertise may not even make them achieve their goal.

The results also support the agency cost theory. Similar to the theoretical assumption of the agency cost theory, weakness in the placement and recognition of internal auditors could make it difficult for IAs to independently compel spending officers to work towards achieving goal congruence and ultimately enhance their effectiveness (Nermeen, 2014, Queku, 2018). This theoretical extrapolation is consistent with the appeared differences in the results of the work of the external auditor and the internal auditor.

The findings suggest that when IAs are highly regarded or given maximum recognition within the administration, leaders will seek their advice in all critical decisions where finance is involved. This will help strengthen financial discipline. On the other hand, if the level of recognition and placement given to them is low, their input would not be regarded in financial decision-making processes, thereby leading to huge loss of money to the state. Further implication of the findings is that the core facet of the internal audit system as noted in the 
definition-independence has been called into question in the MMDAs as exhibited by the findings in this study.

\subsection{Conclusion and Recommendations}

The paper explored that level of threats to IAs placement and recognition and the extent to which these threats could affect the level of IAs independence. Survey design coupled with quantitative analytical procedures was adopted. Mean scale exhibited by the descriptive statistics and inferential statistics from standard regression were used for the investigation. It is concluded that there is a low level of perceived placement of IAs (i.e. high threat to placement) in the MMDAs in the Central Region of Ghana. The study further concludes that the perceived level of recognition given to IAs in the in the MMDAs is very low (i.e. high threat to recognition). Another conclusion is that perceived level of placement and recognition jointly predict the independence status of internal auditors in the MMDAs. Furthermore, the study concludes that perceived level of placement/position and recognition of internal auditors have positive significant effect on their independence in the MMDAs in the Central Region of Ghana.

The implication for the low level of placement of IAs is that it becomes difficult for IAs to stamp their authority in the MMDAs with regards to efficient use of public financial resources. It is therefore recommended that internal auditors or audit units are made separate entities from the main organisational structure in the MMDAs similar to the external auditors. This will mean that all the auditors within the unit will only report to the Chief auditor. It is recommended that this chief auditor will only work and report to higher structure or hierarchy outside the audited state institutions. This could eradicate the control that management of MMDAs has on the internal audit.

The implication of the low perceived recognition given to IAs in the MMDAs is that their consulting role may be relegated. It is therefore recommended that the government should pass a legislative instrument to make internal audit units plays critical role in management decision making at the public services. It is also recommended that internal audit functions should direct and control the use of funds at the local MMDAs.

Further studies may consider expanding the investigation model to incorporate other variables beside placement and recognition. The paper was also limited to the public services in the form of MMDAs in the Central Region of Ghana. More research studies should be conducted in all the other 15 regions as well as well as the State-Owned Enterprises (SOEs).

\section{References}

Adafula, B., Asare, N., Atuilik, W. A., \& Adafula, C. J. (2019). Expectation-performance of internal auditors: Examining views from Ghana. IOSR Journal of Business and Management 17, (4) 10-21

Agbevade, A. (2018). Local Economic Development in Ghana's Local Governance System: The Cases of the Accra Metropolitan, Keta Municipal and Shai Odoku District Assemblies (Doctoral dissertation), University of Ghana.

Ariga B., W. and Gathogo G., (2016).The Examination of the Effectiveness of Internal Audit in County Government of Nakuru. IOSR Journal of Business and Management 18, (4) 2319-7668.

Appiah, D., \& Abdulai, A. G. (2017). Competitive clientelism and the politics of core public sector Journal of Governance and Development, 19(2), 39-46

Asiedu, K. F., \& Deffor, E. W. (2017). Fighting corruption by means of effective internal audit function: Evidence from the Ghanaian public sector. International Journal of Auditing, 21(1), 82-99..

Assfaw, A. M. (2017). Evaluation of effectiveness of internal auditing service in southern public regional bureaus, Ethiopia. International Journal of Management, IT and Engineering, 7(9), 151-195.

Ayagre, P. (2015). Internal Audit Capacity to Enhance Good Governance of Public Sector Organisations: Developing Countries Perspective. Journal of Governance and Development, 11(1), 39-60.

Bell, E., Bryman, A., \& Harley, B. (2018). Business research methods. Oxford university press.

Boone, H. N., \& Boone, D. A. (2012). Analyzing likert data. Journal of extension, 50(2), 1-5.

Dal Mas, L. O., \& Barac, K. (2018). The influence of the chief audit executive's leadership style on factors related to internal audit effectiveness. Managerial Auditing Journal.4 (1) 18-25

Dusoruth, D., (2016). The changing role of Internal Audit. Changing the mind-set. Africa Bank Limited. Oxford university press

Dawuda, A., Ataribanam, S., \& Joseph, A. A. (2017). An Exploratory Study on Management Support Services and Its effects on the Quality Service Delivery of Internal Auditors in the Northern Ghana. Int J Account Res, $5(170), 2$.

Dawuda, A., Aninanya, G. O., \& Alnaa, S. E. (2015). The Organizational Independence of Internal Auditors in Ghana: Empirical Evidence from Local Government. Asian Journal of Economic Modelling, 3(2), 33-45.

Fellows, R. F., \& Liu, A. M. (2015). Research methods for construction. John Wiley \& Sons.

Hay, D., \& Cordery, C. (2018). The value of public sector audit: Literature and history. Journal of Accounting Literature, 40, 1-15. 
Hennink, M., Hutter, I., \& Bailey, A. (2020). Qualitative research methods. SAGE Publications Limited. Bonn Germany

Ibrahim, S., Diibuzie, G., \& Abubakari, M. (2017). The Impact of Internal Control Systems on Financial Performance: The Case of Health Institutions in Upper West Region of Ghana. International Journal of Academic Research in Business and Social Sciences, 7(4), 684-696.

Mokono, R. M., \& Nasieku, T. (2018). Factors Affecting Internal Auditor's Performance in Public Universities in Kenya. John Wiley \& Sons. London UK

Musah, A., Gapketor, E. D., \& Anokye, F. K. (2018). Determinants of internal audit effectiveness in State-Owned Enterprises (SOEs) in Ghana. The Journal of Accounting and Management, 8(1).

Nyaga, K., Kiragu, D. N. U., \& Riro, G. K. (2018). Influence of internal audit independence on internal audit effectiveness in the kirinyaga county government, Kenya.

Nwaobia A. P., Ogundajo G. O., and Theogene N., (2016). Internal Audit Practices and Public Financial Management in Mwanda and Nigeria: Bridging the Transparency Gap in Public Sector Financial Reporting. International Journal of Advanced Academic Research, Social and Management Sciences. ISSN 2488-9849. Vol.2 Issue 10 i Available from: https://www.researchgate.net/publication/319939450.

Pappa, E., \& Filos, J. (2019). Benchmarking the Ethics of Internal Auditors: A Comparative Analysis of Private and Public Sector. SPOUDAI-Journal of Economics and Business, 69(1-2), 30-44.

Queku, I. C. (2017) Value Relevance of International Financial Reporting Standards (IFRS) and Shareholders' Wealth Maximisation: Evidence from Banks in Ghana. International Journal of Advanced Research (IJAR), 5(8), 305-316

Queku, I. C. (2018) International Financial Reporting Standards (IFRS) Compliance and Earning Predictability: Evidence from Banks in Ghana. International Journal of Innovative Research and Advanced Studies (IJAR), 4(8), 102-111

Reichborn-Kjennerud, K., \& Johnsen, Å. (2018). Performance audits and supreme audit institutions' impact on public administration: The case of the office of the auditor general in Norway. Administration \& Society, 50(10), 1422-1446.

Scott, G. K. (2019). Effects of Public Expenditure Management Practices on Service Delivery in the Public Sector: The Case of District Assemblies in Ghana. Journal of Public Administration and Governance, 9(2), 71-92.

Tackie, G., Marfo-Yiadom, E., \& Achina, S. O. (2016). Determinants of internal audit effectiveness in decentralized local government administrative systems. International Journal of Business and Management, 11(11), 184.

Vadasi, C., Bekiaris, M., \& Andrikopoulos, A. (2019). Corporate governance and internal audit: an institutional theory perspective. Corporate Governance: The International Journal of Business in Society.2 (3) 12-24

Yakubu, S. (2017). Factors that influence internal auditors fraud detection capabilities in Ghana (Doctoral dissertation), University of Cape Coast 